\title{
Erratum to: Fingolimod in the treatment algorithm of relapsing remitting multiple sclerosis: a statement of the Central and East European (CEE) MS Expert Group
}

\author{
Franz Fazekas \\ Published online: 9 April 2013 \\ (C) Springer-Verlag Wien 2013
}

L'ubomír Lisý
Department of Neurology, Bratislava, Slovakia

Ivan Milanov

University Hospital „Saint Naum“, Neurology Clinic, Sofia, Bulgaria

Panayiotis Panayiotou

Aretaieio Private Hospital, Nicosia, Cyprus

Sasa Sega Jazbec

Department of Neurology, Ljubljana, Slovenia

Radomír Taláb

Department of Neurology, Hradec Kralove, Czech Republic

Latchezar Traykov

University Hospital Alexandrovska, Neurology Clinic, Sofia, Bulgaria

Peter Turčáni

Department of Neurology, Bratislava, Slovakia

Karl Vass

Univ.-Klinik für Neurologie, Wien, Austria

Norbert Vella

Department of Neurology, Msida MSD, Malta

Eva Havrdová

Department of Neurology, Prague, Czech Republic

We apologize for the error, and we regret any confusion or inconvenience it may have caused.

The online version of the original article can be found unde doi: 10.1007/s10354-012-0123-y

F. Fazekas $(\bowtie)$

Department of Neurology, Medical University of Graz,

Auenbruggerplatz 22, $8036 \mathrm{Graz}$, Austria

e-mail: franz.fazekas@medunigraz.at 